\section{$\underset{\substack{\text { hommes } \\ \text { \& migrations }}}{ }$}

\section{Hommes \& migrations}

Revue française de référence sur les dynamiques

migratoires

$1301 \mid 2013$

Migrations et mondes ruraux

\title{
Martin Melkonian, Arménienne
}

Paris, Maurice Nadeau, 2012, 120 pages, 19,50€

\section{Mustapha Harzoune}

\section{(2) OpenEdition}

\section{Journals}

\section{Édition électronique}

URL : http://journals.openedition.org/hommesmigrations/1965

DOI : 10.4000/hommesmigrations.1965

ISSN : 2262-3353

\section{Éditeur}

Musée national de l'histoire de l'immigration

\section{Édition imprimée}

Date de publication : 1 janvier 2013

Pagination : 209-210

ISBN : 978-2-919040-21-6

ISSN : $1142-852 X$

\section{Référence électronique}

Mustapha Harzoune, « Martin Melkonian, Arménienne », Hommes \& migrations [En ligne], 1301 | 2013, mis en ligne le 29 mai 2013, consulté le 22 septembre 2020. URL : http://journals.openedition.org/ hommesmigrations/1965; DOI : https://doi.org/10.4000/hommesmigrations. 1965 


\title{
Martin Melkonian, Arménienne
}

\author{
Paris, Maurice Nadeau, 2012, 120 pages, 19,50€
}

\author{
Mustapha Harzoune
}

\section{RÉFÉRENCE}

Martin Melkonian, Arménienne, Paris, Maurice Nadeau, 2012, 120 pages, 19,50€

1 L'écriture de Martin Melkonian progresse sur une ligne délicate, celle des émotions qui naissent de traces incertaines, de lieux reconstitués, d'un "flash d'éblouissements", d'une "vaguelette mordorée", d'un "minuscule paquet de mots arméniens" ou de quelques "miettes" . C'est là, au cœur de l'évanescence, que se devinent un visage, une attitude, que s'échappe un parfum de violette, que coulent des larmes ou se distingue l'écho d'une lointaine rumeur. La mémoire est aussi fragile que fut transparente la vie de cette Arménienne, "comme si elle n'avait pas d'histoire; pas de récit; pas de Je". Elle s'appelait Victoria. L'auteur est son fils.

2 À Constantinople, dans le quartier de Beyazid, la famille Handjian échappa aux rafles, déportations et génocide de 1915-1916. Mais, en 1926, il fallut tout de même partir, direction Nice, avec pour visa la mention "sans retour" : exit, du balai, et ne revenez pas! En France, une autre page est à écrire. Celle de l'exil.

Victoria n'a pas laissé d'archives, pas d'albums photos. Juste quelques papiers et lettres "poèmes d'amour entravé" à son fils adressés, et deux ou trois clichés. Avec ces maigres indices, le "piètre enquêteur", comme s'accable lui-même l'auteur, réussit, et avec quelle force!, à reconstituer le fil ténu d'une existence, cette "précarité de coton hydrophile", le quotidien d'une femme invisible, le courage discret d'une modeste immigrée "de nationalité réfugiée arménienne", successivement "couturière, culottière, petite main finisseuse...". L'écriture élégante se déploie dans des phrases descriptives et longues, comme pour mieux retenir le souvenir, s'accrocher à l'instant fugace de la remémoration. Les pensées et les commentaires affleurent, sur la pointe des pieds, comme pour ne pas déranger. Pour espérer "atteindre la nuance de vie d'un être particulier, Victoria", le détail physique et vestimentaire prime ici sur la psychologie. 
4 Le fils s'en retourne sur les lieux de Paris où sa mère a travaillé et vécu : ateliers de tailleur, boutiques-ateliers ou l'appartement de Georges, le frère tant aimé qui détourna pourtant l'héritage familial. Et puis il y eut, après le "gourbi" de la rue d'Aubervilliers, cette modeste chambre sans commodités, au 204, rue du FaubourgSaint-Martin, quartier populeux où l'argot se disputait alors à la gouaille et à l'accent des faubourgs. C'est sur le tard, à 40 ans, en 1947, que Victoria épouse Yervant. Mariage sans amour, rencontre de deux solitudes qui deviendra avec l'arrivée, trois ans plus tard, de l'unique fils, Jiraïr, un couple uni et une famille. Avec si "peu de vocables à sa disposition", Victoria ne parle pas beaucoup. Ou à peine. Elle aime en silence. Elle fait face à la vie, en silence. L'amour des siens et le renoncement pour viatiques. "Heureusement, songe-t-elle, les sentiments ne se prononcent pas; n'ont pas d'accent étranger ; ne nécessitent pas une articulation spéciale. Le silence est leur royaume."

Jiraïr grandit entre deux langues : celle "de l'amour", le français, et l'autre, "l'arménien de Constantinople-Istanbul”, qui s'est infiltrée et chemine mystérieusement en lui. Très tôt, le père est paralysé, le gamin souffre d'anémie. Victoria travaille. Victoria soigne. Victoria élève son "fiston prometteur", "la promesse", celle de la réussite scolaire, de l'éducation comme un investissement. "Ne me traîne pas de malheur en malheur", lui écritelle un jour. En 1965, grâce à l'association des paralysés de France, la famille obtient un appartement à La Courneuve. Plus tard, veuve et seule, Victoria souhaite revenir à Paris. "Après tout, elle se sent autant Parisienne que Constantinopolitaine, et serait à même de revendiquer une citoyenneté d'un type particulier combinant géographie et rêverie. Aucune ligne de démarcation n'est tracée en elle." Victoria referme la parenthèse dans un dernier appartement, au numéro 13 de la rue des Amiraux. La "ressortissante étrangère", née à Constantinople, est enterrée à Avranches, dans la Manche.

6 Qu'il y a loin entre "le prestige de Beyazid" et la condition d'immigrée à Paris. C'est "la dégringolade des apparences". Victoria, "épave parmi les épaves", s'est échouée sur "lîle de la pauvreté", dans un quotidien "où le noir l'emporte si souvent". Pourtant, sur les rares photos de mariage ou de famille, Victoria, pour donner le change, "surpose" : "Chaque pose ou chaque surpose apparait avec la marque spéciale de la revanche. De la revanche et du rappel. C'est mieux qu'un 'Voilà comment j'aurais dû être'. Peut-être un 'Voilà comment je suis restée'. Fidèle à un nous enfermé dans une jarre dormant au fond des eaux du Bosphore. [...] La surpose: une dignité plutôt qu'une vanité; une endurance plutôt qu'une dignité. Le langage d'une femme d'origine arménienne en terre franque." Car le temps et la distance n'effacent rien : l'octogénaire Victoria savoure encore des tiropitakias, cousins des beureks, chez un traiteur grec de la rue du Poteau et ferme les yeux: "Ce sont alors les retrouvailles éclairs avec le Bosphore"... "C'est joyeux. Elle se souvient. Elle oublie."

7 Arménienne est un très beau texte sur la mémoire et le temps. Sur la perte aussi, née des bifurcations de l'existence, de l'exil, des générations qui passent, d'un fils qui prend le large : "Plus j'affiche mon présent, plus je gomme son passé. Mieux dit: mon présent aimanté par un avenir libérateur ne s'accorde plus avec son passé enchainé." Récit sur le vieillissement, la solitude comme antichambre de la mort, Arménienne est un long poème d'amour d'un fils à sa mère. "Je ne chasse par l'Arménie ; je l'ignore. Et l'ignorant, je respire ou crois respirer. Je méconnais le redéploiement infini de l'être vers l'origine, cette origine qui tient lieu d'ego. Le lieu par excellence. Le repose-tête?" 